\title{
RESEARCH
}

Open Access

\section{The role of correlated factors based on Pender health promotion model in brushing behavior in the 13-16 years old students of Guilan, Iran}

Robabeh Haghi ${ }^{1}$, Asieh Ashouri ${ }^{2}$, Mahmood Karimy ${ }^{3}$, Nooshin Rouhani-Tonekaboni ${ }^{4}$, Parisa Kasmaei ${ }^{4^{*}}$, Farahnaz Pakdaman ${ }^{5}$ and Iraj Zareban ${ }^{6}$

\begin{abstract}
Background: Tooth decay is one of the diseases that is closely related to people's behaviors and it can have adverse effects on their performance and their success in the future. Brushing twice a day is the simplest and most effective way to reduce tooth decay. The study aim was to determining the roles of correlational factors based on the Pender's health promotion model in brushing behavior of ninth grade students at urban public schools of Guilan province during the academic year 2019.

Methods: The present study was cross-sectional and had a descriptive-analytical type. We performed the multistage random sampling on 761 ninth-grade students (374 girls and 387 boys) at urban public schools of six counties (ten cities) of Guilan province in 2019. The primary tool was a questionnaire on oral health behaviors focusing on brushing behavior. In the present study, which was conducted only on brushing behavior, we revised and changed the initial questionnaire during the sessions of the research team, and then confirmed its validity and reliability. The questionnaire consisted of three parts, demographic characteristics, constructs of health promotion model, and brushing behavior. We analyzed data in SPSS 21 using regression models.

Results: $20.1 \%$ of students brushed their teeth at least twice a day. Optimal behavior had a statistically significant relationship with parents' education level, and gender. Based on the regression model, the health promotion model constructs described $58 \%$ of the variance of the commitment to plan of action. Perceived self-efficacy, situational influences, and perceived barriers of action had significantly stronger relationships with commitment to plan of action respectively. Multiple logistic regression analysis indicated that one-unit increase in scores of commitment to plan of action and self-efficacy increased the chance of desired behavior by 12 and $14 \%$ respectively.

(Continued on next page)
\end{abstract}

\footnotetext{
*Correspondence: kasmayparisa@yahoo.com; parisa_kasmaei@gums.ac.ir ${ }^{4}$ Department of Health Education and Promotion, Research Center of Health and Environment, School of Health, Guilan University of Medical Sciences, 41857-33411, Realat St., Rasht, Iran

Full list of author information is available at the end of the article
}

C C The Author(s). 2021 Open Access This article is licensed under a Creative Commons Attribution 4.0 International License, which permits use, sharing, adaptation, distribution and reproduction in any medium or format, as long as you give appropriate credit to the original author(s) and the source, provide a link to the Creative Commons licence, and indicate if changes were made. The images or other third party material in this article are included in the article's Creative Commons licence, unless indicated otherwise in a credit line to the material. If material is not included in the article's Creative Commons licence and your intended use is not permitted by statutory regulation or exceeds the permitted use, you will need to obtain permission directly from the copyright holder. To view a copy of this licence, visit http://creativecommons.org/licenses/by/4.0/ The Creative Commons Public Domain Dedication waiver (http://creativecommons.org/publicdomain/zero/1.0/) applies to the data made available in this article, unless otherwise stated in a credit line to the data. 
(Continued from previous page)

Conclusion: Due to the low rate of brushing behavior in the students and the predictive power of the health promotion model in brushing behavior, we suggest planning and implementation of educational interventions for this group with an emphasis on influencing the commitment to plan of action, self-efficacy, and also the level of knowledge.

Keywords: Brushing behavior, Students, Health promotion Model (HPM)

\section{Background}

The World Health Organization (WHO) considers oral health as a necessity and part of public health in life and indicates that low oral health can have a profound effect on quality of life and affects the overall health of humans [1]. Oral and dental diseases, especially dental caries and periodontal diseases, are more common in the world [2]. When tooth decay goes untreated, it can lead to pain. In deep carious lesions, the risk of pulp involvement and abscesses increases, which usually causes swelling and discomfort when chewing. Candida, osteomyelitis, or sepsis due to dental infection leading to hospitalization have been reported in countries with poor access to dental services $[1,3]$.

Using a toothbrush is the first and most practical and common way to clean teeth [4]. Self-care recommendations emphasize brushing twice a day (optimal behavior) [5]. Based on the (Childhood and Adolescence Surveillance and Prevention of Adult Non-communicable disease study) Caspian study in Iran, $23.1 \%$ of students in Iran brush their teeth more than once a day, and the lowest and highest rates were in Kerman (16.66\%) and Kermanshah (33.75\%) respectively. The rate was $23.5 \%$ in Guilan students [6].

Adolescence is a difficult and challenging transition from childhood dependence to the independence and responsibility of youth and adulthood [7, 8]. Emphasizing adolescents' responsibilities without any coercion can help them accept their new role [8]. Identifying the effective factors on oral health behaviors in students and as a result of this, designing appropriate educational interventions, is necessary to improve these behaviors [3].Previous studies found that pay attention to prevention and oral health in students is a key strategy to promote oral health in society, and the first step in prevention and oral health of students is to identify the determinants of their behavior $[8,9]$.

Behavioral and health experts use various theories and models to identify barriers and facilitators of behavior among which Pender's health promotion model (HPM) is comprehensive. The HPM states that cognitiveperceptual factors (perceived benefits, barriers, and selfefficacy), and modifying factors (demographic variables, interpersonal influences, and behavioral factors) are considered to interact with each other to shape and influence an individual's health-promoting behaviors. The approach of this model is self-actualization in order to be healthier (not the absence of disease), so it is an approach-oriented or competence-oriented model [10, 11]. The dimensions of HPM are as follows: Perceived self-efficacy: The individuals' belief in their ability to organize and implement a specific flow of activity or performance. Perceived barriers: They refer to the individual perception associated with lack of access, lack of suitability, cost, difficulty or time-consuming nature of a particular behavior. Perceived benefits: They refer to action anticipating benefits, psychological visualization of positive or behavior-reinforcing consequences. Interpersonal influences: knowledge about other individuals' behavior, beliefs, or attitudes. Situational influences: Individuals' perceptions and cognitions of any situation or context that can facilitate the person's behavior or prevent it. Commitment to plan of action: A behavioral event that leads a person towards certain behavior in the case of avoiding competitive demands (Fig. 1) [10, 12].

Given that various constructs have been introduced as the strongest predictors of oral-health-related behaviors, including brushing behavior, based on the studies and the above-mentioned model [13, 14], the present study aimed to determine the roles of correlational factors based on the Pender's health promotion model in brushing behavior of ninth-grade students at urban schools of Gilan in Iran.

\section{Methods \\ Study design and sampling}

In the cross-sectional study, the participants included 761 ninth-grade students at urban public schools of Guilan province in the academic year of 2019. The necessary minimum sample size was 501 according to a study by Pakpour et al. [15] in which $30 \%$ of ninth-grade students reported that they regularly brushed their teeth by taking into account the $4 \%$ error of approximation, and 0.05 type-I error probability. The sample size became 708 according to the loss of data at a maximum of $15 \%$ of the samples and the coefficient of plan equal to 1.2.

For familiarity of samples for the entire Guilan province, we selected Rasht, Talesh, Fuman, Anzali, Rudbar, and Langarud counties by a convenience method. For selection of samples, we conducted multi-cluster random 


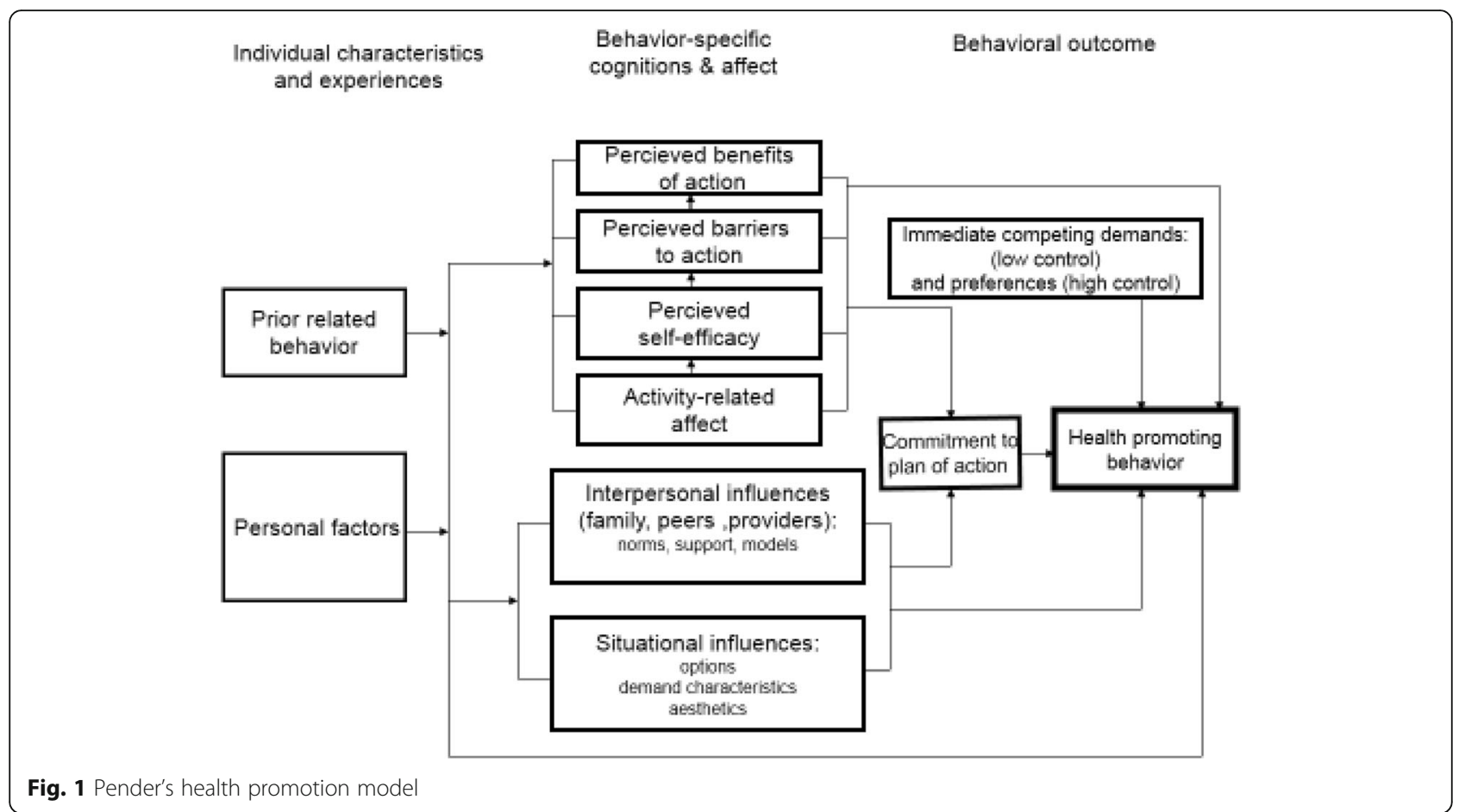

sampling and selected Rasht, Lasht-e Nesha, Khoshkebijar, Fuman, Anzali, Rudbar, Rahmatabad, Langarud, and Kumeleh by a random systematic method. At the next stage, we prepared a list of public schools according to the number of students in each county, and selected the schools $(n=29)$ using the simple random sampling, and then selected a class from each school. Given the demographic distribution of relatively equal male and female students, we equally performed sampling of each city. Inclusion criteria: ninth-grade students at public schools of Guilan province, no Orthodontics, presence in the research process, written consent form of students, parents and school principals, and no periodontal disease, which was determined by the oral clinical examination of a health instructor and dentist.

Exclusion criterion: incomplete questionnaire.

\section{Measures}

Data collection tool was a questionnaire consisting of 3 parts, the first part of which included demographic characteristics. This section contained items on city of residence, age, gender, level of study, birth rank, parents job, parental education, number of children in the family, and the economic situation (The economic situation was

Table 1 Description of the structures of the health promotion model in the studied students

\begin{tabular}{|c|c|c|c|c|c|c|c|}
\hline Variable & $\begin{array}{l}\text { Number of } \\
\text { questions }\end{array}$ & $\begin{array}{l}\text { Cronbach's alpha } \\
\text { coefficients }\end{array}$ & Average & $\begin{array}{l}\text { Standard } \\
\text { deviation }\end{array}$ & $\begin{array}{l}\text { Range of } \\
\text { achievable } \\
\text { values }\end{array}$ & $\begin{array}{l}\text { Range of values } \\
\text { obtained }\end{array}$ & $\begin{array}{l}\text { Percentage of average } \\
\text { score obtained }\end{array}$ \\
\hline $\begin{array}{l}\text { Activity related } \\
\text { affect }\end{array}$ & 8 & 0.76 & 30.74 & 5.34 & $8-40$ & $8-40$ & 71 \\
\hline $\begin{array}{l}\text { Perceived self- } \\
\text { efficacy }\end{array}$ & 7 & 0.85 & 23.33 & 6.52 & $7-35$ & $7-35$ & 58 \\
\hline $\begin{array}{l}\text { Perceived barriers } \\
\text { of action }\end{array}$ & 13 & 0.85 & 31.22 & 10.14 & $13-65$ & $13-65$ & 35 \\
\hline $\begin{array}{l}\text { Perceived benefits } \\
\text { of action }\end{array}$ & 9 & 0.62 & 63.45 & 4.60 & $9-45$ & $17-45$ & 69 \\
\hline $\begin{array}{l}\text { Interpersonal } \\
\text { influences }\end{array}$ & 13 & 0.81 & 45.08 & 10.16 & $13-65$ & $13-65$ & 55 \\
\hline $\begin{array}{l}\text { Situational } \\
\text { influences }\end{array}$ & 9 & 0.76 & 24.54 & 6.63 & $9-45$ & $9-45$ & 43 \\
\hline $\begin{array}{l}\text { Commitment to } \\
\text { plan of action }\end{array}$ & 3 & 0.79 & 9 & 3.21 & $3-15$ & $3-15$ & 51 \\
\hline
\end{tabular}


measured according to asking students how they assessed their economic status. The possible response categories were good, medium and bad). the second part included the health promotion model constructs. This section was contained of seven constructs derived from 62 items. Table 1 presents the number of questions and range of values that can be obtained for these two parts. The last part of the questionnaire included a question about the frequency of brushing per day. Brushing twice a day (favorable behavior) received score 1 , and the lower frequency received score 0 (undesirable behavior).

We determined validity and reliability of the primary tools according to a questionnaire by Morowati et al. [16], and face validity was surveyed by asking questions from 20 ninth-grade students. They mentioned ambiguities and shortcomings and eventually the research team revised it and made fundamental changes (item impact score $=5$ ).

A panel of 8 experts ( 3 specialists in epidemiology, 3 specialists in health education,and two dentistry specialists) evaluated questions based on relevance. After removing some questions and making modification, the rates of content validity index, and content validity ratio were 0.85 and 0.80 respectively for all constructs. To investigate the reliability of tool, 40 students (20 girls and 20 boys) completed the questionnaires twice at an interval of a week, and the internal consistency was calculated using the Cronbach's alpha (Table 1).

\section{Statistical analysis}

We analyzed data in SPSS21. We used descriptive indices of frequency (frequency percentage), mean (standard deviation), or median (range of changes) according to the variable (quantitative and qualitative) and possible distribution (normal and abnormal). We used the multiple logistic regression model to investigate the predictability of demographic characteristics, score of each construct of the model with behavior (desired behavior and at least 2 brushing per day) [5] by controlling the possible confounding variables. We considered $P<0.05$ as the significance of the test.

\section{Results}

In the present study, 761 students participated most of whom were in the age group of 15 years, and $50.9 \%$ of them were boys. 33.4 and $34.4 \%$ of fathers and mothers respectively had high school diplomas. $55.3 \%$ of fathers were "self-employed" and 79\% of mothers were "housewives". 53.5\% of students had two children in their family. $53.2 \%$ of students think that the economic situation is 'medium '(Table 2).

A total of $48.7 \%$ of students brushed their teeth at least once a day and $20.1 \%$ twice a day (Table 3). There were statistically significant relationships between the frequency of brushing and gender, and parents' education level $(P<0.001)$, so that students with more literate parents and female students had more desirable behavior (Table 4).

The highest mean scores of the behavior-feeling constructs belonged to perceived benefits, perceived selfefficacy, interpersonal influences, commitment to plan of action, situational influences, and perceived barriers respectively (Table 5).

Using a multiple linear regression model for determining the relationships of other constructs of the health promotion model with the commitment to plan of action, it was found that $58 \%$ of the variance of the dependent variable (commitment to plan of action) was described by the constructs. Based on the multiple linear regression model, the perceived self-efficacy, situational influences, and perceived barriers respectively had stronger significant relationships with commitment to plan of action (Table 6).

The commitment to plan of action, self-efficacy, and situational influences were significant according to the evaluation of odds ratio in predicting brushing behavior at least twice a day in students based on the health promotion model constructs using multiple logistic regression analysis by "Enter" method. Based on results of logistic regression and assuming that the other variables of the model were constant, one-unit increase in the score of commitment to plan of action enhanced the odds ratio of brushing behavior by $14 \%$ for brushing at least twice a day. One-unit increase in self-efficacy enhanced the odds ratio of brushing behavior by $12 \%$ for brushing at least twice a day (Table 7).

\section{Discussion}

The results of the present study indicated that the optimal brushing behavior was $20.1 \%$ in students. The result was consistent with studies in Iran that reported the optimal brushing behavior of 17.4 to $18.2 \%$ [15, 17]. In other studies conducted abroad, they reported brushing behavior at least twice a day in students in India, Bangladesh, and Nepal from 24 to $37.4 \%$ that were close to the present results $[18-20]$ and the behavior was reported to be from 68 to $95.2 \%$ in studies by Kırtıloğlu et al. in Turkish students [21], Soroye et al. in Nigeria [22], Vettore et al. in the Brazilian adolescents [23], and $67.2 \%$ in a study by Peltzer et al. on students from 26 countries [24], 92.1\% in a study by Rimondini et al. in Italian students [25], and $95 \%$ in a study by Jensen et al. [26] in different age groups in Sweden and the observed difference could be due to differences in income of countries, parents' education level, gender, the way of understanding the issues, self-esteem, difference of ethnic groups and migration, cultures, different beliefs and 
Table 2 Description of demographic characteristics of the studied students (number $=761$ people)

\begin{tabular}{|c|c|c|c|}
\hline \multicolumn{2}{|l|}{ Specifications } & \multirow{2}{*}{$\begin{array}{l}\text { Abundance } \\
484\end{array}$} & \multirow{2}{*}{$\begin{array}{l}\text { Percentage } \\
63.6\end{array}$} \\
\hline City of residence & Rasht, Khoshkbijar, Lasht Nasha & & \\
\hline & Talesh & 60 & 7.9 \\
\hline & Foman & 53 & 7 \\
\hline & Anzali & 70 & 9.2 \\
\hline & Rodbar, Rahmat abad & 77 & 10.1 \\
\hline & Langerod, Komle & 17 & 2.2 \\
\hline \multirow[t]{2}{*}{ Gender } & Girl & 374 & 49.1 \\
\hline & Boy & 387 & 50.9 \\
\hline \multirow[t]{3}{*}{ Age } & 14 and less & 191 & 25.1 \\
\hline & 15 & 473 & 62.2 \\
\hline & 16 & 97 & 12.7 \\
\hline \multirow[t]{4}{*}{ Number of children in the family } & 1 & 138 & 18.1 \\
\hline & 2 & 407 & 53.5 \\
\hline & 3 & 151 & 20.0 \\
\hline & 4 and above & 59 & 7.8 \\
\hline \multirow[t]{4}{*}{ Birth rank } & 1 & 387 & 50.9 \\
\hline & 2 & 255 & 33.6 \\
\hline & 3 & 76 & 10.0 \\
\hline & 4 and more & 42 & 5.5 \\
\hline \multirow[t]{5}{*}{ Father's job } & Employee & 171 & 22.5 \\
\hline & manual worker & 74 & 9.7 \\
\hline & Free & 421 & 55.3 \\
\hline & the farmer & 28 & 3.7 \\
\hline & Retired & 61 & 8.1 \\
\hline \multirow[t]{6}{*}{ Mother's job } & housewife & 601 & 79 \\
\hline & Employee & 92 & 12.1 \\
\hline & manual worker & 5 & 0.7 \\
\hline & Free & 56 & 7.4 \\
\hline & the farmer & 2 & 0.3 \\
\hline & Retired & 4 & 0.5 \\
\hline \multirow[t]{5}{*}{ Father Education } & illiterate & 22 & 2.9 \\
\hline & Primary & 104 & 13.7 \\
\hline & Middle school or high school & 199 & 26.1 \\
\hline & diploma & 254 & 33.4 \\
\hline & Post-diploma, bachelor's degree and higher & 178 & 23.4 \\
\hline \multirow[t]{5}{*}{ Mother's education } & illiterate & 25 & 3.3 \\
\hline & Primary & 112 & 14.7 \\
\hline & Middle school or high school & 202 & 26.5 \\
\hline & diploma & 262 & 34.4 \\
\hline & Post-diploma, bachelor's degree and higher & 160 & 21 \\
\hline \multirow[t]{3}{*}{ The economic situation } & Bad & 17 & 2.2 \\
\hline & medium & 405 & 53.2 \\
\hline & Good & 337 & 44.3 \\
\hline
\end{tabular}


Table 3 Description of the frequency of brushing according to the statements of the studied students

\begin{tabular}{lll}
\hline Specifications & Abundance & Percentage \\
\hline They do not brush at all. & 17 & 2.2 \\
Brush less than once a day or irregularly. & 373 & 49.0 \\
They brush once a day. & 218 & 28.6 \\
They brush twice or more a day. & 153 & 20.1 \\
\hline
\end{tabular}

habits in the field of oral health behavior, and integrated education of oral hygiene at schools.

Our findings indicated that students' good brushing behavior had a statistically significant relationship with parents' education level; and students, who had parents with higher education, significantly had better brushing behavior. The finding was consistent with studies by Vakili et al. [13], Pakpour et al. [15], who reported a significant relationship between parents' education levels and good behavior. However, a study by Casanova et al.

Table 4 Relationship between demographic characteristics and brushing behavior in the studied students

\begin{tabular}{|c|c|c|c|c|c|c|c|}
\hline \multirow[t]{2}{*}{ Level } & & \multicolumn{2}{|c|}{$\begin{array}{l}\text { Brush at least } 2 \text { times a } \\
\text { day }\end{array}$} & \multicolumn{2}{|c|}{$\begin{array}{l}\text { Brush less than } 2 \text { times } \\
\text { a day }\end{array}$} & \multirow[t]{2}{*}{ Total } & \multirow[t]{2}{*}{$\begin{array}{l}p \text { - } \\
\text { value }\end{array}$} \\
\hline & & Abundance & Percentage & Abundance & $\begin{array}{l}\text { Percentage } \\
\text { Pen }\end{array}$ & & \\
\hline \multirow[t]{2}{*}{ Gender } & Girl & 279 & 74.6 & 95 & 25.4 & 374 & 0.001 \\
\hline & Boy & 329 & 85.0 & 58 & 15.0 & 384 & \\
\hline \multirow[t]{3}{*}{ Age } & $14-13$ & 150 & 78.5 & 41 & 21.5 & 191 & 0.733 \\
\hline & 15 & 378 & 79.9 & 95 & 20.1 & 473 & \\
\hline & 16 & 80 & 82.5 & 17 & 17.5 & 97 & \\
\hline \multirow[t]{4}{*}{ Number of children in the family } & 1 & 111 & 80.4 & 27 & 19.6 & 138 & 0.958 \\
\hline & 2 & 326 & 80.1 & 81 & 19.9 & 407 & \\
\hline & 3 & 118 & 78.1 & 33 & 21.9 & 151 & \\
\hline & 4 and above & 47 & 79.9 & 12 & 20.3 & 59 & \\
\hline \multirow[t]{4}{*}{ Birth rank } & 1 & 308 & 79.6 & 79 & 20.4 & 387 & 0.950 \\
\hline & 2 & 203 & 79.6 & 52 & 20.4 & 255 & \\
\hline & 3 & 61 & 80.3 & 15 & 19.7 & 76 & \\
\hline & 4 and more & 35 & 93.3 & 7 & 16.7 & 42 & \\
\hline \multirow[t]{5}{*}{ Father's job } & Employee & 129 & 75.4 & 42 & 24.6 & 171 & 0.230 \\
\hline & manual worker & 65 & 87.8 & 9 & 12.2 & 74 & \\
\hline & Free & 336 & 79.8 & 85 & 14.3 & 421 & \\
\hline & the farmer & 24 & 85.7 & 4 & 19.7 & 28 & \\
\hline & Retired & 49 & 80.3 & 12 & 23.3 & 61 & \\
\hline \multirow[t]{2}{*}{ Mother's job } & housewife & 122 & 76.7 & 37 & 23.3 & 159 & 0.276 \\
\hline & Non-housewife & 485 & 80.7 & 116 & 19.3 & 601 & \\
\hline \multirow[t]{5}{*}{ Father Education } & illiterate & 21 & 95.5 & 1 & 4.5 & 22 & 0.016 \\
\hline & Primary & 93 & 89.4 & 11 & 10.6 & 104 & \\
\hline & Middle school or high school & 160 & 80.4 & 39 & 19.6 & 199 & \\
\hline & diploma & 196 & 77.2 & 58 & 22.8 & 254 & \\
\hline & Post-diploma, bachelor's degree and higher & 135 & 75.8 & 43 & 24.2 & 178 & \\
\hline \multirow[t]{5}{*}{ Mother's education } & illiterate & 21 & 77.2 & 4 & 16.0 & 25 & 0.008 \\
\hline & Primary & 98 & 75.8 & 14 & 12.5 & 112 & \\
\hline & Middle school or high school & 172 & 84.0 & 30 & 14.9 & 202 & \\
\hline & diploma & 198 & 87.5 & 64 & 24.4 & 262 & \\
\hline & Post-diploma, bachelor's degree and higher & 119 & 85.1 & 41 & 25.6 & 160 & \\
\hline \multirow[t]{2}{*}{ The economic situation } & Good & 263 & 78.0 & 74 & 22.0 & 337 & 0.269 \\
\hline & Medium / bad & 343 & 81.3 & 79 & 18.7 & 422 & \\
\hline
\end{tabular}


Table 5 Description of the structures of the health promotion model in the studied students

\begin{tabular}{|c|c|c|c|c|c|c|c|}
\hline Variable & $\begin{array}{l}\text { Number of } \\
\text { questions }\end{array}$ & $\begin{array}{l}\text { Cronbach's alpha } \\
\text { coefficients }\end{array}$ & Average & $\begin{array}{l}\text { Standard } \\
\text { deviation }\end{array}$ & $\begin{array}{l}\text { Range of } \\
\text { achievable } \\
\text { values }\end{array}$ & $\begin{array}{l}\text { Range of values } \\
\text { obtained }\end{array}$ & $\begin{array}{l}\text { Percentage of average } \\
\text { score obtained }\end{array}$ \\
\hline $\begin{array}{l}\text { Activity related } \\
\text { affect }\end{array}$ & 8 & 0.76 & 30.74 & 5.34 & $8-40$ & $8-40$ & 71 \\
\hline $\begin{array}{l}\text { Perceived self- } \\
\text { efficacy }\end{array}$ & 7 & 0.85 & 23.33 & 6.52 & $7-35$ & $7-35$ & 58 \\
\hline $\begin{array}{l}\text { Perceived barriers } \\
\text { of action }\end{array}$ & 13 & 0.85 & 31.22 & 10.14 & $13-65$ & $13-65$ & 35 \\
\hline $\begin{array}{l}\text { Perceived benefits } \\
\text { of action }\end{array}$ & 9 & 0.62 & 63.45 & 4.60 & $9-45$ & $17-45$ & 69 \\
\hline $\begin{array}{l}\text { Interpersonal } \\
\text { influences }\end{array}$ & 13 & 0.81 & 45.08 & 10.16 & $13-65$ & $13-65$ & 55 \\
\hline $\begin{array}{l}\text { Situational } \\
\text { influences }\end{array}$ & 9 & 0.76 & 24.54 & 6.63 & $9-45$ & $9-45$ & 43 \\
\hline $\begin{array}{l}\text { Commitment to } \\
\text { plan of action }\end{array}$ & 3 & 0.79 & 9 & 3.21 & $3-15$ & $3-15$ & 51 \\
\hline
\end{tabular}

[27] in Mexican students did not show any significant relationship between parental education levels and frequency of brushing probably due to cultural and social differences in the research group. A possible reason for the high level of good behavior in students with highly educated parents can indicate high health literacy in their parents. Other possible reasons may be that parents are considered as role models for students and positive effects on oral health behaviors; hence, the parents' roles should be considered in designing the educational interventions.

Our findings indicated that brushing behavior at least twice a day was higher in female students than male students. The results were consistent with most studies on this field $[18,24,28]$. A possible reason for this finding is that women care more about the beauty of their body and appearance, and thus their health than men. Therefore, they pay more attention to their health as an effective factor to increase the beauty and appearance of the body. Understanding belief systems relating to health issues is crucial in any culture for developing health promotion programs in that cultural context.

In the present study, health promotion model constructs were able to describe $58 \%$ of the variance of commitment to plan of action. Banaye Jeddi et al., [29] predicted model constructs by $26.4 \%$ of the variance of commitment to plan of action. As seen in our study, the predictive power of model constructs was high in commitment to plan of action; and the perceived selfefficacy, situational influences, and perceived barriers were the strongest predictors of commitment to plan of action. In a study by Goodarzi et al. [30] perceived selfefficacy was the strongest predictors, and in a study by Banaye Jeddi et al. [29], the perceived barriers and situational influences were the strongest predictors of the commitment to plan of action. In the present study, the important role of self-efficacy in predicting commitment to plan of action indicated that planning and implementing the educational interventions with an aim to increase self-efficacy could be effective in promoting commitment to plan of action. Given that influencing on

Table 6 Regression coefficients and 95\% confidence interval of students in predicting the commitment to plan of action based on the constructs using multiple linear regression model by Enter method

\begin{tabular}{|c|c|c|c|c|c|c|c|c|}
\hline \multirow[t]{2}{*}{ Variable } & \multicolumn{2}{|c|}{ Non-standard coefficient (B) } & \multirow{2}{*}{$\begin{array}{l}\text { Standard } \\
\text { coefficient } \\
\text { (B) }\end{array}$} & \multirow[t]{2}{*}{$\mathbf{T}$} & \multirow[t]{2}{*}{$\begin{array}{l}\text { Probability } \\
\text { value }\end{array}$} & \multicolumn{2}{|c|}{$\begin{array}{l}95 \% \text { confidence interval for regression } \\
\text { coefficients (B) }\end{array}$} & \multirow[t]{2}{*}{$\mathrm{R} 2$} \\
\hline & Coefficient & The standard error & & & & Low limit & upper line & \\
\hline Constant number & -0.06 & 0.89 & & -0.07 & 0.94 & -1.81 & 1.68 & $58 \%$ \\
\hline Activity related affect & 0.05 & 0.01 & 0.09 & 3.18 & $<0.001$ & 0.21 & 0.09 & \\
\hline Perceived self -efficacy & 0.24 & 0.01 & 0.49 & 14.64 & $<0.001$ & 0.21 & 0.27 & \\
\hline Perceived barriers of action & -0.04 & 0.01 & -0.13 & -4.38 & $<0.001$ & -0.63 & -0.02 & \\
\hline Perceived benefits of action & 0.00 & 0.01 & 0.00 & 0.22 & 0.82 & -0.03 & 0.04 & \\
\hline Interpersonal influences & 0.01 & 0.00 & 0.03 & 1.27 & 0.20 & -0.00 & 0.02 & \\
\hline Situational influences & 0.10 & 0.00 & 0.21 & 7.38 & $<0.001$ & 0.07 & 0.12 & \\
\hline
\end{tabular}


Table 7 Odds ratio and 95\% confidence interval in predicting students' brushing behavior (at least 2 times per day) based on the health promotion model constructs using multiple logistic regression analysis by Enter method

\begin{tabular}{lllll}
\hline Variable & $\begin{array}{l}\text { Odds } \\
\text { ratio }\end{array}$ & \multicolumn{2}{c}{$\mathbf{9 5 \% \text { confidence interval }}$} & upper line \\
\cline { 3 - 4 } & Low limit & 1.264 & 1.050 \\
\hline Commitment to plan of action & 1.143 & 1.034 & 1.181 & 0.009 \\
Activity related affect & 0.997 & 0.946 & 1.006 & 0.903 \\
Perceived self- efficacy & 1.117 & 1.056 & 1.031 & 0.001 \\
Perceived barriers of action & 0.978 & 0.950 & 1.042 & 0.437 \\
Perceived benefits of action & 0.980 & 0.931 & 0.99 & 0.194 \\
Interpersonal influences & 1.016 & 0.992 & 0.03 & \\
Situational influences & 0.96 & &
\end{tabular}

barriers is not easily possible in most cases, an educational intervention should target the processes of reducing barriers by identifying real and perceived barriers and paying special attention to the most important ones [31].

According to the prediction of desired behavior, the commitment to plan of action and self-efficacy were significant predictors of behavior, and one-unit increase in the above constructs enhanced the chance of performing the behavior by 14 and $12 \%$ respectively. Consistent with results of our study, Zeidi et al. [32], Banaye Jeddi et al. [33], and Mehri et al. [34], reported that the commitment to plan of action was the strongest predictor of oral health behavior. However, results of studies by Morowati et al. [16], Charkazi et al. [35], and Vakili et al. [13], were inconsistent with our study. Different results of the above studies may be due to different economic, social, cultural and age conditions in the research groups. Commitment to plan of action starts up the behavioral event. This commitment leads people towards the behaviors; and the higher commitment to a specific activity increases the possibility of maintaining healthy behavior at the whole time. The commitment to plan of action refers to planning for its change, start, maintenance, and management [10]. Therefore, the more committed you are to planning to perform a behavior regardless of constraints, conditions, and possibilities, the more likely you are to engage in that behavior, and the more successful you are in achieving that goal. Since behavior is a complicated phenomenon and its change is a continuous, permanent, and goal-based process, it is impossible to achieve a logical and purposeful result without relying on the specified and planned commitment that requires knowledge about future opportunities and threats and prediction of the way of facing with them. Commitment to plan of action can lead to desirable behavior when it creates more attractiveness than other behaviors because otherwise other behaviors are preferred. It is worthwhile to consider the above point in designing educational interventions for the research group.

Consistent with our study, findings of many studies emphasize the role of self-efficacy as a significance predictor of oral health behavior [13, 14, 30, 32-36]. Self-efficacy is not about a person's skills, but about his or her judgment of what he or she can do, considering all the skills he has [10]. Higher self-efficacy creates a positive feeling about the behavior and decreases perceived barriers. Therefore, its increase in students by creating the ability to overcome the existing barriers on the pathway to observance of the oral health can maintain the continuity of desired behavior. In other words, the students' belief in their personal and inner abilities to overcome barriers is a key factor in the adhering the recommendations of oral hygiene. Given the results of the present study, we suggest a higher focus on the identification of internal and environmental perceived barriers of students in the field of oral health behavior, and then the use of strategies such as verbal persuasion, stimulating and encouraging emotional states and vicarious learning resulting from observing the performance of others to improve students' self-efficacy.

The research limitations included the use of selfreport tools and the cross-sectional nature of study; hence, we could not infer the causal relationships.

\section{Conclusion}

According to the results, the rate of optimal behavior (Brush at least 2 times a day) among Iranian students was low. Commitment to action plan and perceived self-efficacy were the most important constructs in predicting optimal behavior in students. It seems that educational interventions targeting brushing behavior might benefit using the Health Promotion Model to improve adolescents' oral health. 


\section{Abbreviations}

WHO: World Health Organization; OR: Odds Ratio; SD: Standard Deviation SPSS: Statistical Package for Social Sciences; CVR: Content validity ratio; CVI: Content validity index

\section{Supplementary Information}

The online version contains supplementary material available at https://doi. org/10.1186/s13052-021-01063-y.

Additional file 1.

\section{Acknowledgments}

The present article was derived from a master's thesis in health education approved by Gilan University of Medical Sciences. We are grateful to the esteemed research deputy of Gilan University of Medical Sciences for their financial and spiritual support in the research and also students who had great cooperation in conducting the research.

\section{Authors 'contributions}

$\mathrm{RH}$ : principal investigator, designed the study, collected the data, performed the statistical analyses, and wrote the manuscript. AA and NRT: co-supervisor de-signed the study, guided the statistical analyses and writing the manuscript. MK and FP: participated in the design of the study, guided the statistical analyses and writing the manuscript. PK: main supervisor, designed the study, guided the statistical analyses and writing the manuscript. All authors read and approved the final manuscript.

\section{Funding}

The research was fully funded by Guilan University of Medical Sciences, Iran. The funding body didn't play any role in the design of the study and collection, analysis, and interpretation of data and in writing the manuscript.

\section{Availability of data and materials}

The datasets used and/or analyzed during the current study are available from the corresponding author on request.

\section{Declarations}

\section{Ethics approval and consent to participate}

All participants were informed about the study and confidentiality protocols. Written Informed consent was obtained from all the participants. The Ethic Committee of Guilan University of Medical Sciences approved the study protocol (IR.GUMS.REC.1398.24).

\section{Consent for publication}

Not applicable.

\section{Competing interests}

The authors declare that they have no competing interests.

\section{Author details}

${ }^{1}$ Department of Health Education and Promotion, School of Health, Guilan University of Medical Sciences, Rasht, Iran. ${ }^{2}$ Department of Cardiology, Cardiovascular Diseases Research CenterHeshmat Hospital, School of Medicine, Guilan University of Medical Sciences, Rasht, Iran. ${ }^{3}$ Social Determinants of Health Research Center, Saveh University of Medical Sciences, Saveh, Iran. ${ }^{4}$ Department of Health Education and Promotion, Research Center of Health and Environment, School of Health, Guilan University of Medical Sciences, 41857-33411, Realat St., Rasht, Iran. ${ }^{5}$ Department of Elderly and Middle-aged Health, Vice-chancellor of Health, Guilan University of Medical Sciences, Rasht, Iran. ${ }^{6}$ Health Promotion Research Center, Zahedan University of Medical Science, Zahedan, Iran.

\section{Received: 20 October 2020 Accepted: 27 April 2021}

Published online: 12 May 2021

\section{References}

1. Koch G, Poulsen S. Pediatric dentistry: a clinical approach. 9th ed. Tehran: Royan pazhouh; 2013.
2. Newman M, Takei H, Klokkevold P. Curranza's clinical periodentology, vol. 1. 12th ed. Tehran: Shayan nemodar; 2015.

3. Karimy $M$, et al. Oral health behavior among school children aged 11-13 years in Saveh, Iran: an evaluation of a theory-driven intervention. BMC Pediatr. 2020;20(1):1-9.

4. Jeffrey D, Mcdonald R. Dentistry for the child and adolescent, vol. 1. 9th ed. Tehran: Royan pazhouh; 2016.

5. Makarem A. National book of pediatric dentistry, vol. 1. Tehran: Jahade daneshgahi; 2016

6. Motlagh S, et al. Health care behaviors and disease risk factors in Iranian students. Esfehan: Samand; 2016.

7. Araban $\mathrm{M}$, et al. Prevalence and factors associated with disruptive behavior among Iranian students during 2015: a cross-sectional study. Ital J Pediatr. 2020;46(1):1-7.

8. Naseri-Salahshour $\mathrm{V}$, et al. The effect of oral health promotion program on early dental decay in students: a cluster randomized controlled trial. J Caring Sci. 2019:8(2):105-10. https://doi.org/10.15171/jcs.2019.015.

9. Mohamadkhah $F$, et al. Effects of lecturing on selfcare oral health behaviors of elementary students. Med J Islam Repub Iran. 2014;28:86.

10. Pender, N.J., et al., Health promotion in nursing practice. 2015.

11. Karimy $\mathrm{M}$, et al. Does the theory-driven program affect the risky behavior of drug injecting users in a healthy city? A quasi-experimental study. Med J Islam Repub Iran. 2016:30:314.

12. Karataş T, Polat Ü. Effect of nurse-led program on the exercise behavior of coronary artery patients: Pender's health promotion Model. Patient Educ Couns. 2020. https://doi.org/10.1016/j.pec.2020.10.003.

13. Vakili $\mathrm{M}$, et al. Determinants of oral health behaviors among high school students in Shahrekord, Iran based on Health Promotion model. Am Dent Hyg Assoc. 2011;85(1):39-48

14. Seo Y-J, Ha Y. Gender differences in predictors of physical activity among Korean college students based on the Health Promotion Model. Asian/Pac Island Nurs J. 2019:4(1):1-10. https://doi.org/10.31372/20190401.1000.

15. Pakpour-Hajiagha A, Hidarnia A, Hajizadeh E. Oral health status and its determinants in a sample of Iranian adolescents in Qazvin (2010). J Qazvin Univ Med Sci. 2011;15(3):54-60

16. Morowatisharifabad M, Shirazi KK. Determinants of oral health behaviors among preuniversity (12th-grade) students in Yazd (Iran): an application of the health promotion model. Fam Community Health. 2007:30(4):342-50. https://doi.org/10.1097/01.FCH.0000290546.33328.76.

17. Kasmaei P, Amin Shokravi F, Hidarnia A, Hajizadeh E, Atrkar-Roushan Z, Karimzadeh Shirazi K, et al. Brushing behavior among young adolescents: does perceived severity matter. BMC Public Health. 2014;14(1):8. https://doi. org/10.1186/1471-2458-14-8

18. Mehta A, Kaur G. Oral health-related knowledge, attitude, and practices among 12-year-old schoolchildren studying in rural areas of Panchkula, India. Indian J Dent Res. 2012;23(2):293. https://doi.org/10.4103/0970-9290.100446.

19. Haque SE, Rahman M, Itsuko K, Mutahara M, Kayako S, Tsutsumi A, et al. Effect of a school-based oral health education in preventing untreated dental caries and increasing knowledge, attitude, and practices among adolescents in Bangladesh. BMC Oral Health. 2016;16(1):44. https:/doi.org/10.1186/s12903-016-0202-3.

20. Prasai Dixit L, Shakya A, Shrestha M, Shrestha A. Dental caries prevalence, oral health knowledge and practice among indigenous Chepang school children of Nepal. BMC Oral Health. 2013;13(1):20. https://doi.org/10.1186/14 72-6831-13-20.

21. Kırtıloğlu T, Yavuz ÜS. An assessment of oral self-care in the student population of a Turkish university. Public Health. 2006;120(10):953-7. https:// doi.org/10.1016/j.puhe.2006.05.006.

22. Soroye $\mathrm{MO}$, Braimoh $\mathrm{BO}$. Oral health practices and associated caries experience among secondary school students in Lagos state, Nigeria. J Oral Res Rev. 2017;9(1):16. https://doi.org/10.4103/2249-4987.201399.

23. Vettore MV, Moysés SJ, Sardinha LMV, Iser BPM. Socioeconomic status, toothbrushing frequency, and health-related behaviors in adolescents: an analysis using the PeNSE database. Cad Saude Publica. 2012;28(suppl):s10113. https://doi.org/10.1590/S0102-311X2012001300011.

24. Peltzer K, Pengpid S. Oral health behaviour and social and health factors in university students from 26 low, middle and high income countries. Int J Environ Res Public Health. 2014;11(12):12247-60. https://doi.org/10.3390/ ijerph111212247.

25. Rimondini L, Zolfanelli B, Bernardi F, Bez C. Self-preventive oral behavior in an Italian university student population. J Clin Periodontol. 2001:28(3):20711. https://doi.org/10.1034/j.1600-051x.2001.028003207.x. 
26. Jensen O, Gabre P, Sköld UM, Birkhed D. Is the use of fluoride toothpaste optimal? Knowledge, attitudes and behaviour concerning fluoride toothpaste and toothbrushing in different age groups in Sweden. Community Dent Oral Epidemiol. 2012:40(2):175-84. https://doi.org/10.1111/ j.1600-0528.2011.00658.x.

27. Casanova-Rosado AJ, et al. Tooth brushing frequency in Mexican schoolchildren and associated socio-demographic, socioeconomic, and dental variables. Med Sci Monit. 2014;20:938.

28. Al Subait AA, et al. Oral health knowledge, attitude and behavior among students of age 10-18 years old attending Jenadriyah festival Riyadh; a cross-sectional study. Saudi J Dental Res. 2016;7(1):45-50. https://doi.org/1 0.1016/j.sjdr.2015.05.001.

29. Banaye Jeddi $\mathrm{M}$, et al. Cognitive-behavioral determinants of oral health in students: an application of Pender's Health Promotion Model. J Educ Community Health. 2016;3(2):1-8.

30. Goodarzi A, et al. Predicting oral health behaviors among Iranian students by using health belief model. J Educ Health Promot. 2019:8:10.

31. Karimy, M., H. Azarpira, and M. Araban, Using health belief model constructs to examine differences in adherence to pap test recommendations among Iranian women. Asian Pacific journal of cancer prevention: APJCP. 2017; 18(5):1389.

32. Mohammadi Zeidi I, Alijanzadeh M, Hajiagha AP. Factors predicting oral health-related behaviors in diabetic patients using Pender's Oral Health Promotion Model. J Isfahan Dental School. 2016;12(2):198-83.

33. Banaye Jeddi $\mathrm{M}$, et al. Cognitive-Behavioral Determinants of Oral Health in Students: an Application of Pender's Health Promotion Model. J Educ Community health. 2016;3(2):8-1.

34. Mehri A, Morowatisharifabad M. Utilizing the health promotion model to predict oral health behaviors in the student of islamic azad university of Sabzevar. J Dental School Shahid Beheshti Univ Med Sci. 2009;22(1):81-7.

35. Charkazi A, et al. Predicting oral health behavior using the health promotion model among school students: a cross-sectional survey. Int J Pediatr. 2016; 4(7):2069-77.

36. Moodi $\mathrm{M}$, et al. Predictive power of health promotion model constructs in relation to oral health behaviors among students in elementary school students year 2016-17. J Birjand Univ Med Sci. 2018;24(4):324-35.

\section{Publisher's Note}

Springer Nature remains neutral with regard to jurisdictional claims in published maps and institutional affiliations.

Ready to submit your research? Choose BMC and benefit from:

- fast, convenient online submission

- thorough peer review by experienced researchers in your field

- rapid publication on acceptance

- support for research data, including large and complex data types

- gold Open Access which fosters wider collaboration and increased citations

- maximum visibility for your research: over $100 \mathrm{M}$ website views per year

At $\mathrm{BMC}$, research is always in progress.

Learn more biomedcentral.com/submissions 